Research Article

\title{
Development of Liquid-Based Tea and Its Antidiabetic Effect
}

\author{
Sheba Culas $\mathbb{D}^{1}{ }^{1}$ R. A. U. J Marapana, ${ }^{1}$ I. R. Palangasinghe, ${ }^{2}$ and A. C. Liyanage $^{2}$ \\ ${ }^{1}$ Department of Food Science and Technology, University of Sri Jayewardenepura, Nugegoda 10250, Sri Lanka \\ ${ }^{2}$ Department of Food Technology, Dilmah Ceylon Tea Company PLC, Peliyagoda 11830, Sri Lanka \\ Correspondence should be addressed to Sheba Culas; culassheba@gmail.com
}

Received 21 September 2020; Revised 23 December 2020; Accepted 16 January 2021; Published 1 February 2021

Academic Editor: Jean-Marie Nedelec

Copyright (c) 2021 Sheba Culas et al. This is an open access article distributed under the Creative Commons Attribution License, which permits unrestricted use, distribution, and reproduction in any medium, provided the original work is properly cited.

Diabetes mellitus is a chronic disease resulting from insulin resistance which is now a growing concern. Tea from Camellia sinensis is a beverage consisting of many health benefits, one of which is its antidiabetic properties due to the presence of polyphenols. In this study, tea products made from bark extracts of Cinnamomum zeylanicum (cinnamon) and leaves of Artocarpus heterophyllus (Jak) were evaluated for their antidiabetic effects by testing for the polyphenol content, antioxidant content, and alpha-amylase inhibition activity. The product made from tea and Jak yielded the highest polyphenol content of $53.58 \pm 0.12$ gallic acid equivalent (GAE) $\mathrm{mg} / 100 \mathrm{~g}$ of the raw material, while cinnamon tea yielded a polyphenol content of $22.69 \pm 0.45 \mathrm{GAE} \mathrm{mg} / 100 \mathrm{~g}$. The halfmaximum inhibitory concentration (IC50) value of $5.3915 \mathrm{mg} / \mathrm{L}$ was obtained for the Jak brew and $5.4935 \mathrm{mg} / \mathrm{L}$ for cinnamon ice tea demonstrating that cinnamon has better antioxidant capacity. The percentage inhibition of alpha-amylase showed $31.03 \pm 0.29 \%$ at a concentration of $4 \mu \mathrm{g} / \mathrm{mL}$ of Jak tea and $13.27 \pm 0.32 \%$ at a concentration of $17.5 \mu \mathrm{g} / \mathrm{mL}$ of cinnamon brew. The maximum yield of cinnamon polyphenols of $35.30 \pm 1.10 \mathrm{GAE} \mathrm{mg} / 100 \mathrm{~g}$ of the raw material was obtained under an extraction temperature of $75^{\circ} \mathrm{C}$, extraction time of 30 minutes, and extraction ratio of $1: 8$ (cinnamon: water). This study suggests that cinnamon bark extracts and Jak leaves' brew can be potentially useful for the control of diabetes mellitus, and the optimal conditions can be used as an indicator for scaled-up industrial production.

\section{Introduction}

Diabetes mellitus is a growing concern around the globe according to Weatherspoon [1]. Diabetes mellitus (DM) is a chronic disease caused by deficiency in the production of insulin by the pancreas or due to the ineffectiveness of insulin produced. The deficiency in the production of insulin can be both inherited and acquired. This will result in increased concentrations of glucose in the blood stream, which can cause harm to the body, in particular, the blood vessels and nerves [2]. While discoveries of medicines and drugs for the treatment of this condition are on the forefront, there is also another growing trend for treatment using natural ingredients that possess antidiabetic properties. Camellia sinensis (tea), Cinnamomum zeylanicum (cinnamon), and Artocarpus heterophyllus (Jak) are three such ingredients having antidiabetic properties [3]. Cinnamomum zeylanicum is indigenous to Sri Lanka and southern parts of India and is known as true cinnamon or "Ceylon cinnamon." According to the study done by Khan and others [3], an unidentified factor that they isolated from cinnamon found to have been involved in the alleviation of the signs and symptoms of diabetes and related diseases to insulin resistance. Studies have been done to show that administration of cinnamon powder highly contributes to the reduction of fasting blood glucose level and that the reduction is dose dependent $[4,5]$. Artocarpus heterophyllus (family Moraceae), commonly known as Jak, is a tropical plant native to South and Southeast Asia [6].

Polyphenols present in these natural ingredients contribute towards the control of diabetes by elevating the activation of insulin reception [7]. In this study that was performed at a leading tea company in Sri Lanka, two tea products made from a combination of tea, cinnamon, and Jak were studied for their antidiabetic properties by evaluating the total polyphenolic content, DPPH scavenging activity, and alpha-amylase inhibition assay. 


\section{Materials and Methods}

2.1. Material Collection. Tea leaves were obtained from a leading tea company in Sri Lanka, while cinnamon bark and Jak leaves were obtained from a reputed herb supplier located at Matale, Sri Lanka. All chemicals used for chemical testing were of analytical grade with highest purity available (>99.5\%).

2.2. Preparation of the Extract. The cinnamon bark was dried using a hot air oven at $60^{\circ} \mathrm{C}$ for 6 hours and was ground using a heavy grinder to obtain cinnamon powder. Then, the cinnamon powder was soaked in water for a period of 24 hours in different ratios $(1: 5,1: 8$, and $1: 10)$ and was extracted at temperatures of 65,75 , and $85^{\circ} \mathrm{C}$ and extraction times of 30,60, and 90 minutes. Following the extraction, the mixture was centrifuged at $6000 \mathrm{rpm}$ for 10 minutes to obtain the filtrate. The polyphenol content of the filtrates was obtained using the ISO 14502-1 Folin-Ciocalteu method [8], and the filtrate that showed the highest polyphenol content was chosen to be used in the development of tea. This filtrate was stored at $4^{\circ} \mathrm{C}$ until usage.

The Jak leaves were brewed in $200 \mathrm{ml}$ hot water $\left(100^{\circ} \mathrm{C}\right)$ for 5 minutes, and then the brew was filtered to obtain the Jak brew. The brew was freshly prepared for each experimental analysis.

2.3. Determination of the Total Polyphenol Content. The total polyphenol content of the two developed products was determined according to the ISO 14502-1 method (Folin-Ciocalteu method for tea). In brief, $1.0 \mathrm{~mL}$ of the diluted sample extract was transferred in duplicate to separate tubes containing $5.0 \mathrm{~mL}$ of a $1 / 10$ dilution of Folin-Ciocalteu's reagent in water. Then, $4.0 \mathrm{~mL}$ of sodium carbonate solution $(7.5 \% \mathrm{w} / \mathrm{v})$ was added. The tubes were then allowed to stand at room temperature for $60 \mathrm{~min}$ before absorbance at $765 \mathrm{~nm}$ was measured against water [8]. The total polyphenolic contents were calculated on the basis of the standard calibration curve of gallic acid and expressed as gallic acid equivalent (GAE), in milligrams per 100 gram of the sample.

2.4. Determination of Free Radical Scavenging Activity. Free radical scavenging activity of the extract was determined by using 1,1-diphenyl-2-picrylhydrazyl (DPPH) freeradical scavenging assay method as described by BrandWilliams et al. [9]. The inhibition percentage was obtained by using the following equation:

$$
(I \%)=\frac{\left(A_{\text {control }}-A_{\text {sample }}\right) * 100}{A_{\text {control }}} .
$$

A curve of percent inhibition or scavenging effect against sample concentrations was plotted, and the concentration of the sample required for 50\% inhibition (IC50) was determined. The value for each of the test sample was presented as the inhibition curve at $50 \%$ or IC50.

\subsection{Determination of Alpha-Amylase Inhibition Assay.} The reducing sugar (maltose equivalent) was quantified to determine the alpha-amylase inhibition assay. The dinitrosalicylic acid (DNS) method described by Miller [10] was adopted with modifications to obtain the maltose equivalent. A blank was prepared without plant extracts and a control without the amylase enzyme, replaced by equal quantities of buffer $(0.02 \mathrm{M}$ sodium phosphate buffer ( $\mathrm{pH} 6.9)$ at $\left.20^{\circ} \mathrm{C}\right)$. The absorbance was measured at $540 \mathrm{~nm}$ using a spectrophotometer. The reducing sugar released from starch was estimated as maltose equivalent from a standard graph. The antidiabetic activity was determined through the inhibition of $\alpha$-amylase which was expressed as a percentage of inhibition and calculated by the following equation:

$$
\% \text { inhibition }=\frac{[(\text { maltose in the control })-(\text { maltose in the sample })-\text { maltose in the blank }] * 100}{\text { maltose in the control }} .
$$

2.6. Statistical Analysis. All tests were carried out in triplicates. The data obtained were analysed using Minitab 17 statistical software, and the differences were considered statistically significant when $p<0.05$.

\section{Results and Discussion}

\subsection{Optimization of Extraction Conditions of Cinnamon.} As identified by Gulcin and others [11], extraction time and temperature are critical as these conditions affect the total polyphenol content in the final extract. The results of the polyphenol content of cinnamon extracted in different ratios in water are given (see Table 1).

It can be seen that the highest TPC is found in the ratio $1: 8$; hence, this ratio was identified as the optimum ratio for the development of the product. However, since the TPC content also differs based on temperature and time conditions, this extraction was carried under different time and temperature conditions to obtain the optimum conditions. The best time-temperature combination for extraction based on the total polyphenol content of the extract was $75^{\circ} \mathrm{C}$ and 30 minutes as shown in Figure 1 (see Table 2).

3.2. Determination of the Total Polyphenol Content. TPC of the products was calculated as GAE, mg per 100 gram of the raw material, used by using the Folin-Ciocalteu reagent, and was given (see Table 3). As illustrated by Kim et al. [12], polyphenols are responsible for insulin-potentiating action. According to the results obtained by Wijewardhana et al. [13], methanolic cinnamon extracted in the ratio of $1: 10$ had a total polyphenolic content of $18.94 \mathrm{mg}$ GAE per $100 \mathrm{~g}$ of 
TABLE 1: Total polyphenol content of cinnamon extracted in different ratios of water.

\begin{tabular}{lc}
\hline Cinnamon : water ratio $(w / v)$ & TPC (mg per 100g of the raw material as GAE) \\
\hline $1: 5$ & $7.50 \pm 0.06$ \\
$1: 8$ & $20.40 \pm 0.30$ \\
$1: 10$ & $19.81 \pm 0.39$ \\
\hline
\end{tabular}

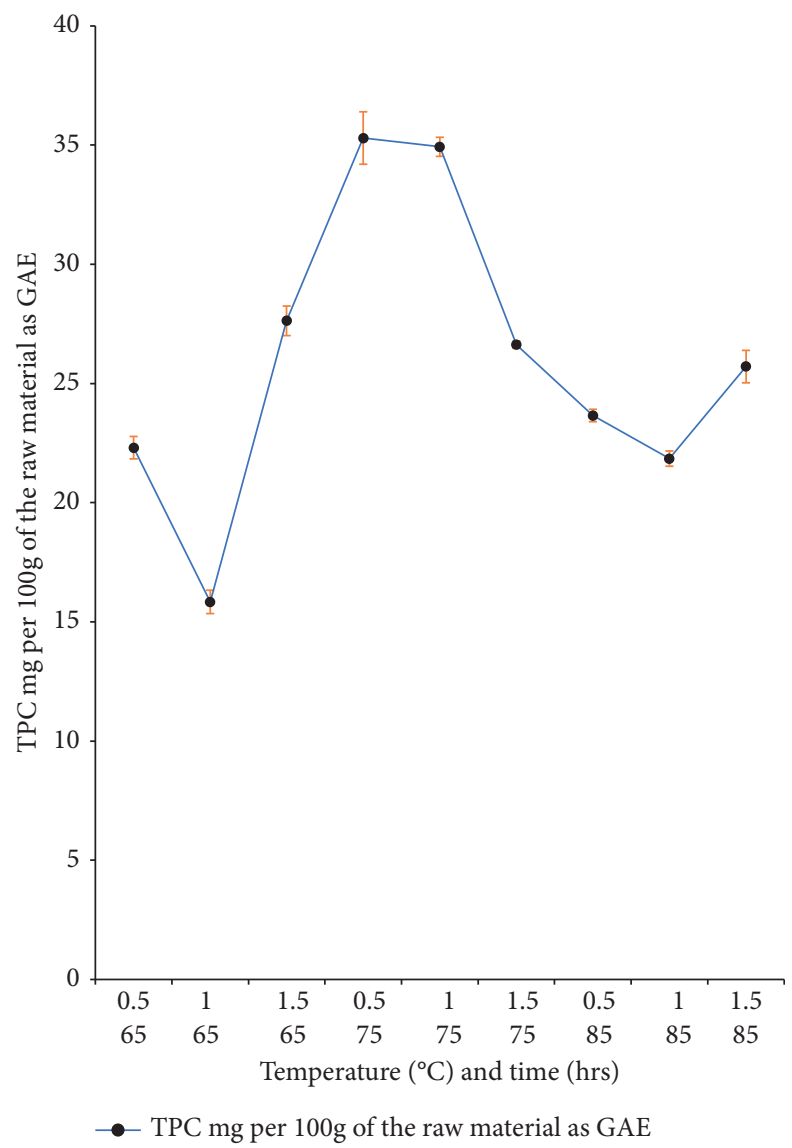

Figure 1: Plot of the total polyphenol content in mg per $100 \mathrm{~g}$ of the raw material as gallic acid equivalent, recorded over different temperature and time combinations. The error bars represent the standard deviation of triplicated measurements in four separate sample runs $(n=144)$.

TABLE 2: Total polyphenol content under different time-temperature conditions.

\begin{tabular}{lcc}
\hline Temperature $\left({ }^{\circ} \mathrm{C}\right)$ & Time $(\mathrm{h})$ & TPC $(\mathrm{mg}$ per $100 \mathrm{~g}$ of the raw material as GAE) \\
\hline 65 & 0.5 & $22.31 \pm 0.47$ \\
65 & 1 & $15.84 \pm 0.49$ \\
65 & 1.5 & $27.63 \pm 0.62$ \\
75 & 0.5 & $35.30 \pm 1.10$ \\
75 & 1 & $34.93 \pm 0.40$ \\
75 & 1.5 & $26.63 \pm 0.15$ \\
85 & 0.5 & $23.66 \pm 0.26$ \\
85 & 1 & $21.85 \pm 0.32$ \\
85 & 1.5 & $25.71 \pm 4.99$ \\
\hline
\end{tabular}

the dry weight. However, the hot water extraction performed in this research for the same ratio of cinnamon and water yielded a higher polyphenol content of $19.96 \mathrm{mg}$ GAE per $100 \mathrm{~g}$ of the dry weight. This difference may be due to the difference in media of extraction and can be explained by the research finding of Mngeni [14], who said that the highest extraction of polyphenols was that of the aqueous extraction compared to other solvents. The research findings by 
TABLE 3: Total polyphenolic content, IC50 value, and alpha-amylase inhibition assay of Jak tea and cinnamon tea.

\begin{tabular}{lccc}
\hline Sample & TPC $(\mathrm{mg} \mathrm{GAE} / 100 \mathrm{~g})$ & IC50 value $(\mathrm{mg} / \mathrm{L})$ & $\alpha$-Amylase inhibition $(\%)$ \\
\hline Jak tea & $53.58 \pm 0.12$ & 5.3915 & $31.03 \pm 0.29$ \\
Cinnamon tea & $22.69 \pm 0.45$ & 5.4935 & $13.27 \pm 0.32$ \\
\hline
\end{tabular}

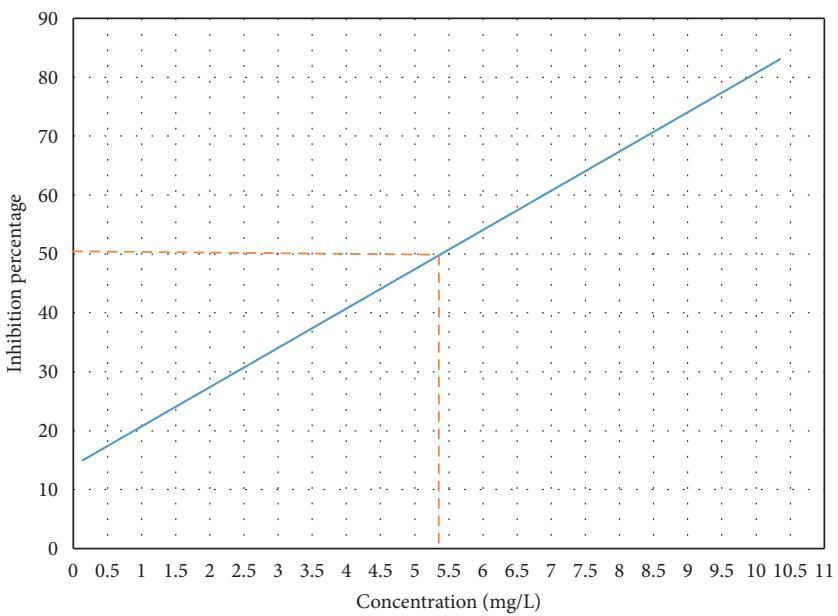

Figure 2: Plot of inhibition percentage with respect to concentration $(\mathrm{mg} / \mathrm{L})$ of triplicated measurements in two separate sample runs of the Artocarpus heterophyllus extract.

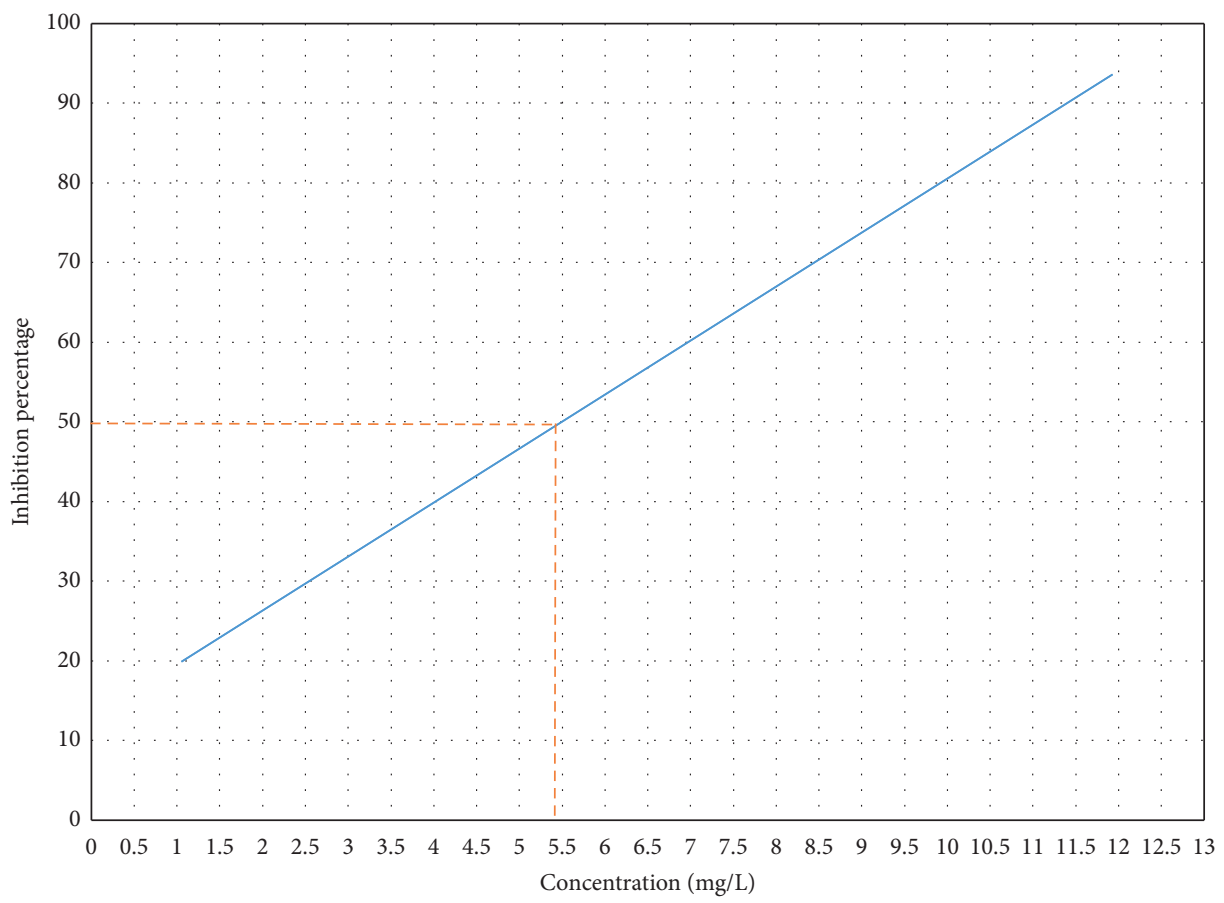

FIGURE 3: Plot of inhibition percentage with respect to concentration $(\mathrm{mg} / \mathrm{L})$ of triplicated measurements in two separate sample runs of Cinnamomum zeylanicum ice tea.

Wijewardhana et al. and Mngeni $[13,14]$ are on par with the current polyphenol content of cinnamon tea which is $22.69 \pm 0.45 \mathrm{mg}$ per $100 \mathrm{~g}$ of the raw material.

Meanwhile, the comparison of the TPC of Jak tea was not feasible due to the limited literature on this subject. However, the results obtained for $200 \mathrm{ml}$ Jak tea by the Folin-Ciocalteu method presented a mean value of
$53.58 \pm 0.12 \mathrm{mg}$ per $100 \mathrm{~g}$ of the raw material as represented in Table 3.

3.3. Determination of Free Radical Scavenging Activity. The prepared extracts of Jak and cinnamon were evaluated using the DPPH test in order to investigate their radical 
scavenging activity. The obtained IC50 values are illustrated in Table 3. The maximum absorbance of DPPH is seen at $515-517 \mathrm{~nm}$. The disappearance of DPPH is measured spectrophotometrically at $517 \mathrm{~nm}$ in the presence of antioxidants. The IC50 value which is the concentration of the antioxidant where $50 \%$ inhibition occurs can then be calculated using the absorbance values.

The concentration of the studied plant extracts required to scavenge $50 \%$ of the DPPH radicals $\left(\mathrm{IC}_{50}\right)$ of the Artocarpus heterophyllus extract was $5.4935 \mathrm{mg} / \mathrm{L}$ (see Figure 2), and for Cinnamomum zeylanicum ice tea, it was $5.3915 \mathrm{mg} / \mathrm{L}$ (see Figure 3).

A research study in Nepal expressed the IC50 value of Artocarpus heterophyllus leaves as $10.69 \mu \mathrm{g} / \mathrm{ml}$ which is almost double the IC50 value obtained in this research which utilized Sri Lankan Jak leaves [15]. This may be due to the difference in the location of the species, varietal differences, and growing conditions such as climate, light intensity, soil type, and agronomic practices.

The smaller the IC50 values, the higher the antioxidant activity. The classification by Feghhi-Najafabadi et al. [16] states that IC $50<50 \mu \mathrm{g} / \mathrm{mL}$ is considered a very powerful antioxidant, IC50 $50-100 \mu \mathrm{g} / \mathrm{mL}$ as a strong antioxidant, IC50 $100-150 \mu \mathrm{g} / \mathrm{mL}$ as intermediate antioxidants, and IC50 $151-200 \mu \mathrm{g} / \mathrm{mL}$ as weak antioxidants. Based on these criteria, the results obtained in this study from the samples analysed can be classified as powerful antioxidants.

3.4. Determination of Alpha-Amylase Inhibition Assay. Alpha-amylase is responsible for the digestion of dietary starch to maltase that in turn is digested into glucose by intestinal alpha-glucosidase. Inhibition of these two enzymes will delay carbohydrate digestion thus lowering the postprandial blood glucose level. In this research, the objective was to investigate the inhibition percentage of alpha-amylase of the developed product by the DNS method. In this research, the extract or the brew that results when the tea bag is brewed produced an inhibition percentage of $31.03 \pm 0.29$ for a concentration of $4 \mu \mathrm{g} / \mathrm{mL}$ for Jak tea, and a concentration of $17.5 \mu \mathrm{g} / \mathrm{mL}$ resulted in an inhibition percentage of $13.27 \pm 0.32$ for cinnamon tea (see Table 3 ).

\section{Conclusions}

The product developed using Artocarpus heterophyllus showed highest TPC, radical scavenging activity, and alphaamylase inhibition activity in comparison to the product developed using Cinnamomum zeylanicum. Therefore, both products have the possibility of acting as antioxidants and potential antidiabetic products. However, a thorough and full-fledged in vivo study is needed to explore the role of these extracts and also their bioactive compounds to determine their antidiabetic and antioxidant activities.

\section{Data Availability}

The data supporting the findings of this study are available within the article.

\section{Conflicts of Interest}

The authors declare that there are no conflicts of interest regarding the publication of this paper.

\section{Acknowledgments}

This research was financially supported by Dilmah Ceylon Tea Company PLC, Sri Lanka.

\section{References}

[1] C. Weatherspoon, Type 2 Diabetes Statistics: Facts and Trends, Medical News Today, Brighton, UK, 2019, https://www. medicalnewstoday.com/articles/318472.php.

[2] A. N. Nagappa, P. A. Thakurdesai, N. Venkat Rao, and J. Singh, "Antidiabetic activity of Terminalia catappa Linn fruits," Journal of Ethnopharmacology, vol. 88, no. 1, pp. $45-50,2003$.

[3] A. Khan, N. Bryden, M. Polansky, and R. Anderson, "Insulin potentiating factor and chromium content of selected foods and spices," Biological Trace Element Research, vol. 24, no. 2-3, pp. 183-188, 1990.

[4] A. Sahib, "Antidiabetic and antioxidant effect of cinnamon in poorly controlled type-2 diabetic Iraqi patients: a randomized, placebo-controlled clinical trial," Journal of Intercultural Ethnopharmacology, vol. 5, no. 2, p. 108, 2016.

[5] S. H. Kim, S. H. Hyun, and S. Y. Choung, "Anti-diabetic effect of cinnamon extract on blood glucose in $\mathrm{db} / \mathrm{db}$ mice," Journal of Ethnopharmacology, vol. 104, no. 1-2, pp. 119-123, 2006.

[6] S. Chackrewarthy, M. Thabrew, M. K. Weerasuriya, and S. Jayasekera, "Evaluation of the hypoglycemic and hypolipidemic effects of an ethylacetate fraction of Artocarpus heterophyllus (jak) leaves in streptozotocin-induced diabetic rats," Pharmacognosy Magazine, vol. 6, no. 23, p. 186, 2010.

[7] C. L. Broadhurst, M. M. Polansky, and R. A. Anderson, "Insulin-like biological activity of culinary and medicinal plant aqueous extracts in vitro," Journal of Agricultural and Food Chemistry, vol. 48, no. 3, pp. 849-852, 2000.

[8] C. Anesini, G. E. Ferraro, and R. Filip, "Total polyphenol content and antioxidant capacity of commercially available tea (Camellia sinensis) in Argentina," Journal of Agricultural and Food Chemistry, vol. 56, no. 19, pp. 9225-9229, 2008.

[9] W. Brand-Williams, M. E. Cuvelier, and C. Berset, "Use of a free radical method to evaluate antioxidant activity," $L W T$ Food Science and Technology, vol. 28, no. 1, pp. 25-30, 1995.

[10] G. L. Miller, "Use of dinitrosalicylic acid reagent for determination of reducing sugar," Analytical Chemistry, vol. 31, no. 3, pp. 426-428, 1959.

[11] I. Gulcin, R. Kaya, A. C. Goren et al., "Anticholinergic, antidiabetic and antioxidant activities of cinnamon (cinnamomum verum) bark extracts: polyphenol contents analysis by LC-MS/MS," International Journal of Food Properties, vol. 22, no. 1, pp. 1511-1526, 2019.

[12] Y. Kim, J. Keogh, and P. Clifton, "Polyphenols and glycemic control," Nutrients, vol. 8, no. 1, pp. 17-34, 2016.

[13] U. Wijewardhana, U. Gunathilaka, and S. Navaratne, "Determination of total phenolic content, radical scavenging activity and total antioxidant capacity of cinnamon bark, black cumin seeds and garlic," International Research Journal of Advanced Engineering and Science, vol. 4, no. 2, pp. 55-57, 2019.

[14] N. Z. Mngeni, "Bioactive compounds from selected medicinal plants used in antidiabetic treatment," Doctoral dissertation, 
Cape Peninsula University of Technology, Cape Town, South Africa, 2017.

[15] N. Thapa, P. Thapa, J. Bhandari, P. Niraula, N. Shrestha, and B. G. Shrestha, "Study of phytochemical, antioxidant and antimicrobial activity of artocarpus heterophyllus," Nepal Journal of Biotechnology, vol. 4, no. 1, pp. 47-53, 2016.

[16] S. Feghhi-Najafabadi, L. Safaeian, and B. Zolfaghari, "In vitro antioxidant effects of different extracts obtained from the leaves and seeds of Allium ampeloprasum subsp. persicum," Journal of Herbmed Pharmacology, vol. 8, no. 3, pp. 256-260, 2019. 